\title{
Djenkolism: case report and literature review
}

This article was published in the following Dove Press journal:

International Medical Case Reports Journal

16 April 2014

Number of times this article has been viewed

\section{Nur C Bunawan' \\ Asghar Rastegar ${ }^{2}$ \\ Kathleen PWhite ${ }^{3}$ \\ Nancy E Wang ${ }^{4}$}

'Alam Sehat Lestari Clinic, West Kalimantan, Borneo, Indonesia;

${ }^{2}$ Section of Nephrology, Department of Medicine, Yale University School of Medicine, New Haven, CT, USA; ${ }^{3}$ General Internal Medicine, Yale University School of Medicine, New Haven, CT, USA; ${ }^{4}$ Department of Surgery and Pediatric Emergency Medicine, Stanford University School of Medicine, Stanford, CA, USA

Video abstract

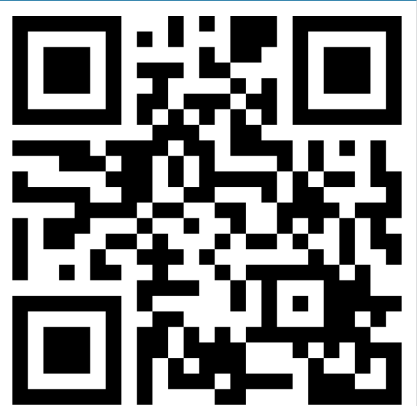

Point your SmartPhone at the code above. If you have a QR code reader the video abstract will appear. Or use: http://dvpr.es/liu3Fr4

Correspondence: Nancy E Wang Pediatric Emergency Medicine, Stanford University School of Medicine, 300 Pasteur Drive, Alway MI2I, Stanford, CA 94305 USA

$\mathrm{Tel}+\mathrm{I} 6507230757$

$\mathrm{Fax}+\mid 6507230121$

Email ewen@stanford.edu
Abstract: Djenkolism is an uncommon but important cause of acute kidney injury. It sporadically occurs after an ingestion of the djenkol bean (Archidendron pauciflorum), which is native to Southeast Asia. The clinical features defining djenkolism include: spasmodic suprapubic and/ or flank pain; urinary obstruction; and acute kidney injury. The precise pathogenesis of acute kidney injury following djenkol ingestion remains unknown. However, it is proposed that an interaction between the characteristics of the ingested beans and the host factors causes hypersaturation of djenkolic acid crystals within the urinary system, resulting in subsequent obstructive nephropathy with sludge, stones, or possible spasms. We report a case of djenkolism from our rural clinic in Borneo, Indonesia. Our systematic literature review identified 96 reported cases of djenkolism. The majority of patients recovered with hydration, bicarbonate therapy, and pain medication. Three patients required surgical intervention; one patient required ureteral stenting for the obstructing djenkolic acid stones. Four of the 96 reported patients died from acute kidney failure. We stress the importance of awareness of djenkolism to guide medical practitioners in the treatment of this rare disease in resource-poor areas in Southeast Asia.

Keywords: djenkolism, acute renal failure, acute kidney injury, tropical medicine

\section{Introduction}

Djenkolism is considered an uncommon but important cause of acute kidney injury in tropical Asia. Djenkolism sporadically results from the ingestion of the djenkol bean (Archidendron pauciflorum) (Figure 1), native to Southeast Asia. Despite its strong smell, the beans are regarded as a delicacy in some areas, including Indonesia. They are consumed raw or prepared in a variety of ways. Djenkolism has a varied clinical presentation ranging from acute kidney injury, urinary obstruction, and spasmodic suprapubic and/or flank pain that occurs within hours of the bean's ingestion. In this report, we describe a case of djenkolism in a remote clinical setting. We also conduct a systematic review of pertinent literature. We stress the importance of clinical findings and supportive care in remote areas where laboratory support is limited.

\section{Case presentation}

A 32-year-old man presented to our rural clinic in Borneo, Indonesia, with 10 hours of severe bilateral flank pain. Two hours after eating ten djenkol beans, the patient experienced acute, bilateral, severe (rated as 10/10), and spasmodic flank pain which radiated to the groin and was accompanied by vomiting. He also experienced difficulty with urination, hematuria, and decreased urine output ( $2 \mathrm{~mL}$ over the course of 12 hours). 


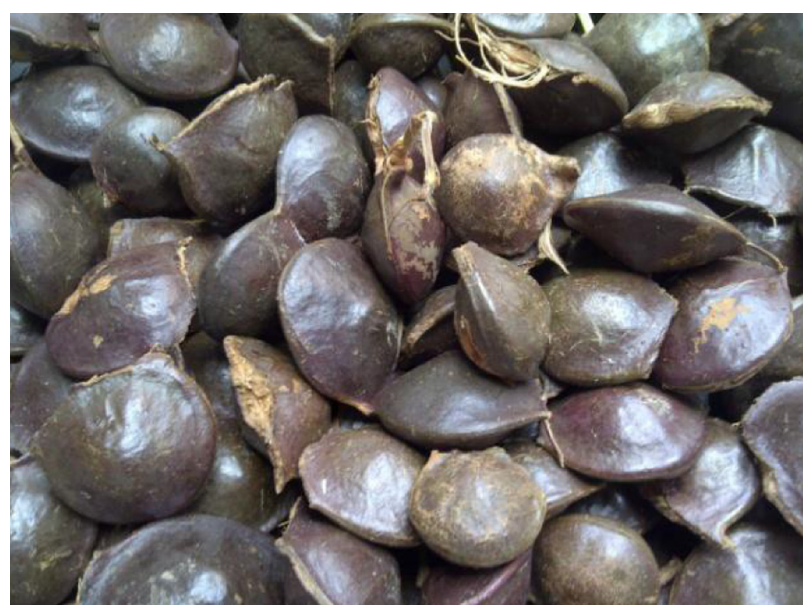

Figure I Djenkol bean.

Note: Photo courtesy of MR Nirmala.

The patient was healthy with no known medical problems. Medical history noted that the patient had experienced a similar episode as a teenager; he did not seek medical attention at that time and recovered after 14 days. The patient had consumed djenkol beans during the interval period between the two episodes without symptoms. He did not have any recent illnesses and had not taken medications prior to or since the onset of pain.

The patient was fully alert and in moderate distress. Vital signs were recorded at the time of treatment: blood pressure at 120/80; heart rate at 77 beats per minute; respiratory rate at 16 breaths per minute; and temperature at $36.5^{\circ} \mathrm{C}$. The patient experienced approximately 2 minutes of severe spasmodic pain every 10 minutes with concurrent vomiting or syncope. Physical examination was notable for the odor of djenkol on his breath, abdominal hyperperistalsis, suprapubic tenderness, and bilateral costovertebral tenderness. Intravenous (IV) access was obtained and an indwelling urinary catheter was placed. The patient was given tramadol $50 \mathrm{mg}$ IV for pain and urged to drink carbonated beverages as tolerated.

An ultrasound of the kidneys revealed bilateral hydronephrosis (Figure 2) with no stones noted. Anuria persisted and was treated with a $2.5 \mathrm{~L}$ normal saline bolus and furosemide $20 \mathrm{mg}$ IV. The patient subsequently urinated $200 \mathrm{~mL}$ of bloody urine with resolution of pain. Upon microscopic exam, the initial urine sample had a specific gravity of 1.020 and 3+ blood, microscopic exam revealed many red blood cells and sediment but no crystals. The patient continued to receive pain medications and IV fluids as needed with resolution of oliguria.

After four days, the patient's other symptoms, including hematuria, resolved. A repeat ultrasound demonstrated mild right-sided hydronephrosis and a normal left kidney. The

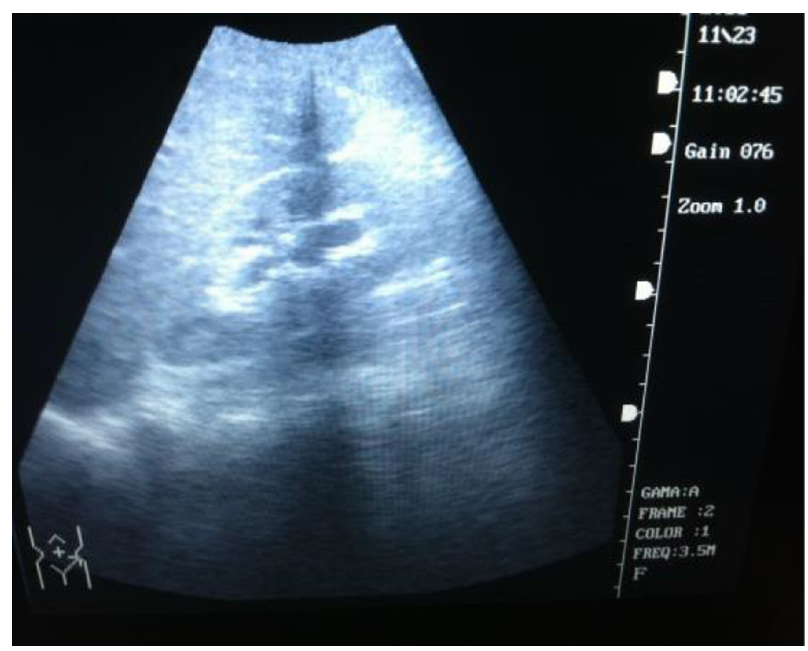

Figure 2 Mild hydronephrosis of left kidney on ultrasound.

patient was discharged on tramadol as needed, encouraged to drink at least $2 \mathrm{~L}$ of fluid per day, and advised to avoid djenkol beans. The patient returned approximately 2 weeks later completely asymptomatic; residual right-sided hydronephrosis had also completely resolved.

\section{Literature review}

A systematic literature review was conducted by searching Ovid MEDLINE, Index Medicus for Southeast Asia Region (IMSEAR), and Ovid Embase. IMSEAR is a database of articles published in selected journals within the World Health Organization Southeast Asian Region. Embase is an online database of biomedical literature published worldwide. The search strategy included medical subject headings (MeSH) terms: (dogfruit) OR (jenko*) OR (djenko*) OR (jering*) OR (jiringa*) OR (archidendron) OR (pauciflorum) OR (neang) OR (niang) OR (dog fruit) OR (Fabaceae).

\section{Search results}

The search on Ovid Medline and Embase resulted in 100 and 164 citations, respectively. The IMSEAR search yielded 16 citations, including ten unique citations. After removing duplicate citations, there were 172 unique articles. Five additional citations were found on reviewing bibliographies of the 172 articles, for a total of 177 references. ${ }^{1-6}$

Upon independent review of 177 articles by two authors (NEW and KPW) a total of 25 references were agreed upon as pertinent either in describing the cases or the clinical entity of djenkolism in terms of clinical presentation, differential diagnosis, pathophysiology, management, or outcome. References involving solely the biochemical study of djenkolic 
acid were excluded. Although we conducted the initial search in all languages, after identifying pertinent references, all but three (which were written before 1945) were available in English. Thus, we decided to limit our review to articles in the English language.

Many articles were reviews. ${ }^{2-7}$ We identified nine articles reporting a total of 96 cases in the Indonesian, Malaysian, Thai, and Singaporean literature. ${ }^{3,6,8-14}$ Some of the cases were cited by more than one article. We were able to obtain all but two of the original articles and only cited the original case report.

Details of available clinical, imaging, and laboratory data varied greatly (Tables 1 and 2). Three articles included 88 patients (with one study of 50 children), while other articles include only one to two cases each. ${ }^{3,6,9}$ Demographics, physical examination, and findings were generally consistent with those found in the review literature, as well as in our patient case. Patient age ranged from $1.5-57$ years with a male predominance $(70 \%)$. The average number of beans consumed was ten; symptom onset occurred between 2 hours- 4 days after ingestion. Major presenting signs and symptoms were: abdominal/loin/colicky pain, 70\%; dysuria, 66\%; oligouria, $59 \%$; hematuria, $55 \%$; and hypertension, $36 \%$.

While there was inconsistent reporting of needle-shaped crystals in the urine, hematuria was consistently reported in the literature. Some cases reported milky/turbid urine. When renal function was documented, creatinine was elevated, ranging from $1.7-14.1 \mathrm{mg} / \mathrm{dL}$ (normal, $0.6-1.3 \mathrm{mg} / \mathrm{dL}$ ). When the blood count was completed, other electrolytes and inflammatory parameters were documented; these measures were normal. There was only one report of human renal biopsy in the English literature. ${ }^{11}$ The majority of patients were treated with hydration and bicarbonate to alkalinize the urine. Cases in which conservative treatment failed were treated with: dialysis (one); surgery (one); urethral and bladder irrigation (one); or ureteral stenting (one). The mortality rate was (four out of 96) or about $4 \%$. Three of the four deaths occurred in children; these deaths were attributed to renal failure with no availability of dialysis. ${ }^{6}$

\section{Discussion}

Djenkol beans are a local delicacy in Indonesia, Malaysia, Southern Thailand, and Myanmar. ${ }^{15}$ The djenkol tree grows up to $25 \mathrm{~m}$ in height. Djenkol pods are dark purple and contain three to eight round and flat beans per pod; they resemble flattened horse chestnuts. ${ }^{3}$ The djenkol bean contains a large amount of the djenkolic acid in the range of $0.3-1.3 \mathrm{~g} / 100 \mathrm{~g}$ wet weight; $93 \%$ of the acid exists in a free state. ${ }^{16}$ The beans

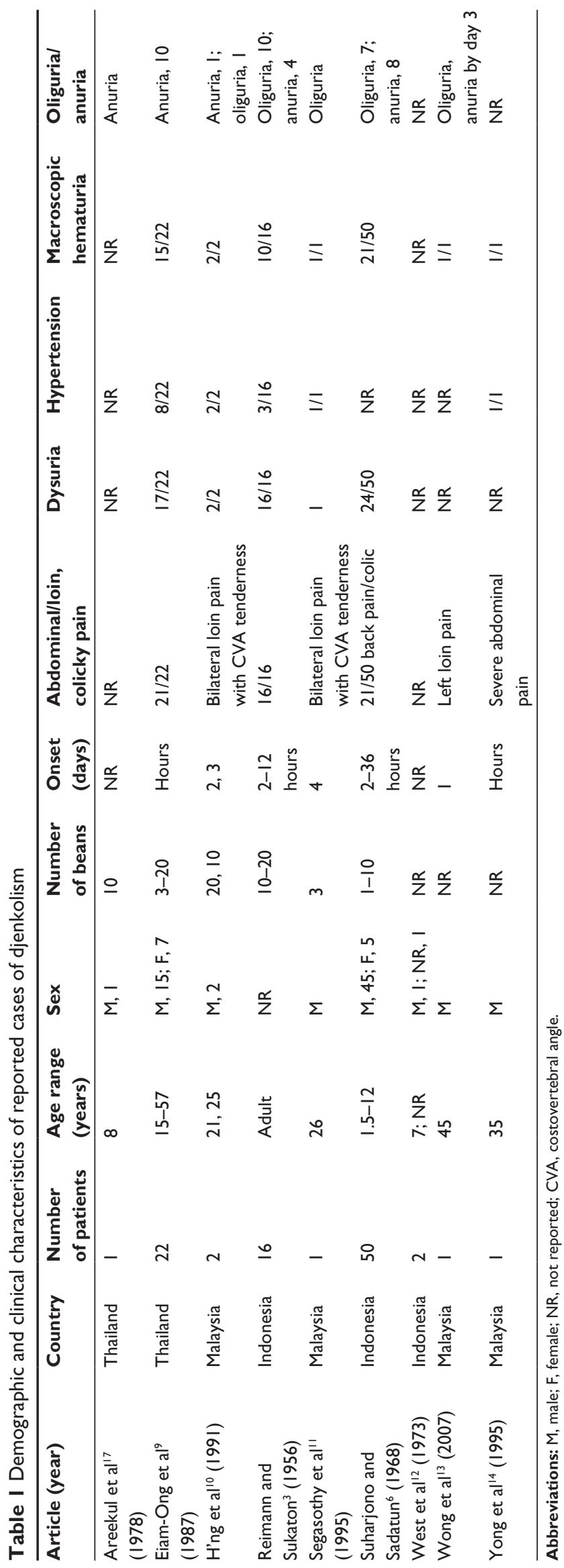




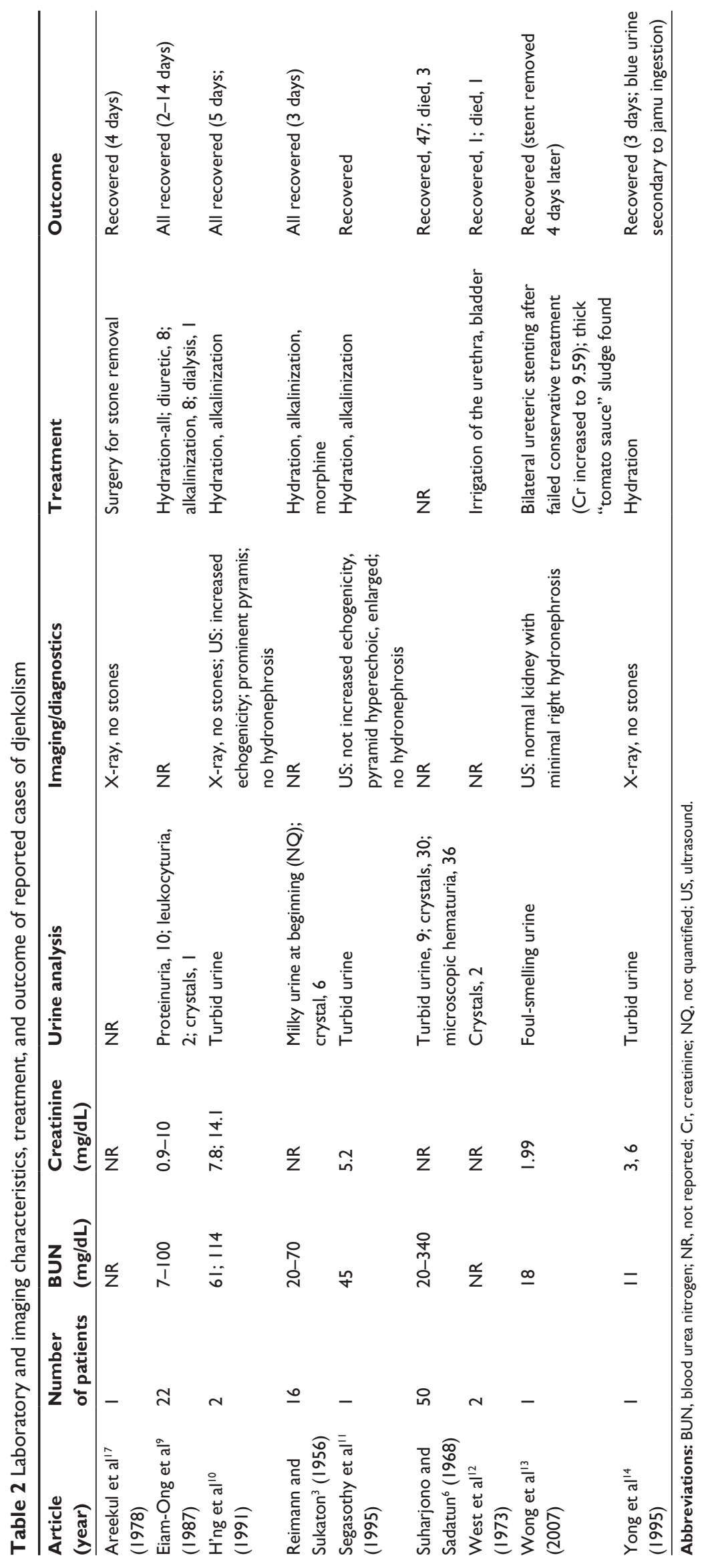


are eaten raw, fried, boiled, or roasted; sometimes, they are served as a dessert. ${ }^{8}$ Regardless of the method of preparation, the ingestion of even one bean causes the breath and urine to have a sulfurous odor. ${ }^{3}$

The clinical syndrome of djenkolism has a substantial male-to-female predominance (7:1) with an increased incidence from September-January, the rainy season, when the djenkol tree is in bloom. ${ }^{10}$ Clinical djenkolism occurs sporadically. Individuals who have had djenkolism in the past do not necessarily have symptoms with subsequent ingestions, as was true in the case of our patient. Symptoms, if they do occur, occur within 2-12 hours of bean ingestion and consist of flank and bladder spasms, dysuria, colic, flatulence, vomiting, and diarrhea or constipation. ${ }^{8}$ Affected persons can first develop a milky urine, which then consistently becomes bloody. Urine analysis demonstrates albumin, epithelial cells, casts, erythrocytes, and sometimes needle-shaped crystals. ${ }^{8}$ Crystal formation is at least partially dependent on $\mathrm{pH}$, as solubility of the djenkolic acid increases significantly in alkaline $\mathrm{pH} .{ }^{17}$

Djenkolism seems to have two presentations: 1) a mild presentation with pain and hematuria corresponding with transient ureteral obstruction with djenkolic acid crystals; and 2) a severe presentation in which hypertension, oliguria, and azotemia can occur. Anuria and death occur rarely. ${ }^{11}$

In areas where laboratory tests are available, anuria corresponds with laboratory markers of acute kidney injury. ${ }^{10}$ The clinical presentation of flank pain, nausea, vomiting, and gross hematuria is most compatible with ureteral and urethral obstruction by djenkolic acid crystals. Crystals may lacerate renal tissue and cause bleeding, or - in some cases obstruction with sludge necessitates passage of a urethral catheter or stent. ${ }^{13,17}$

The pathogenesis of acute kidney injury following djenkol ingestion is not well understood. It is proposed to result from a combination of host factors, as well as characteristics of the specific beans ingested. ${ }^{7}$ Hypersensitivity to a component of the bean has also been suggested to play an etiologic role in djenkolism, given the variability in the dose required for the development of nephrotoxicity. ${ }^{3}$ While experiments in animals have been inconclusive, experiments in rats and mice resulted in clinicopathological findings compatible with acute tubular necrosis (ATN).

Obstruction of the renal tubules by crystals of djenkol acid has been suggested as a mechanism of ATN. Validation of this theory has been confounded by histological challenges: 1) acid crystals are not visible in all animal models (histologic preparation may dissolve the crystals); ${ }^{17}$ and
2) renal biopsies are rarely performed on patients with acute djenkolism (one case report of human renal biopsy demonstrated findings of ATN). ${ }^{11}$

In animal experiments, djenkolic acid crystals were detected in only a few animals, leading some to suggest that renal toxicity could be due to a direct toxic effect of the amino acid or a metabolite. ${ }^{11}$ In conclusion, proposed major mechanisms of renal injury by the djenkol bean include hypersensitivity to or a direct toxic effect of a djenkol bean metabolite, resulting in acute kidney injury and/or urinary tract obstruction by djenkolic acid crystals, sludge, and/or possible ureteral spasms. In extreme cases, this can cause postobstructive failure. It is reasonable to also consider that the severe nausea and vomiting could contribute to dehydration, adding a prerenal element to the kidney injury.

There is a paucity of data on the long-term effects of hematuria secondary to chronic djenkol bean consumption. However, one study of children - those with microscopic asymptomatic hematuria - demonstrated that these children had four times the increased odds of djenkol bean exposure. ${ }^{18}$

The patient seen in our clinic presented with classical findings associated with djenkol bean toxicity. Although we were unable to measure renal function due to lack of diagnostic tests in our rural Indonesian clinic, diagnosis of acute kidney injury in this patient was based on persistent oligouria/anuria following an ingestion of the bean. This scenario is not unusual in the remote areas where djenkol bean ingestion is common, and the diagnosis is made based on clinical presentation and limited laboratory data.

It is reported that the majority of cases resolve within 3 days with supportive care. ${ }^{3}$ Mild djenkolism requires no specific treatment except pain control and hydration. ${ }^{11}$ Severe djenkolism manifested by anuria and presumed acute kidney injury usually is managed with analgesia, aggressive hydration, and alkalinization of the urine with sodium bicarbonate to increase the solubility of djenkolic acid. Due to the lack of availability of sodium bicarbonate in our clinic, we used carbonated beverages to alkalinize the urine. ${ }^{11,12}$ Some cases of severe djenkolism with anuria do not respond to conservative therapy and require surgical intervention. There are case reports of the irrigation of the urethra, placement of urinary catheters, as well as stents to bypass or to resolve urinary obstruction caused by djenkolic acid, sludge, and calculi. ${ }^{13,17}$

Prevention of djenkolism is problematic. Incidence is low. The syndrome is sporadic, and it does not seem to be dependent on the quantity or mode of preparation of the beans. 
Individuals eating from the same dish do not all become symptomatic. Furthermore, an individual's susceptibility to djenkolism and acute kidney injury from the bean is not fixed from one exposure to the next. ${ }^{3,8}$ It has been proposed that boiling the bean in dilute alkali would remove the acid. ${ }^{12}$ However, the acceptance of this practice is unknown.

\section{Conclusion}

There is increasing awareness of the importance of and myriad of causes of acute kidney injury in the tropics. It is well established that djenkolism is an important cause of acute kidney injury in Southeast Asia. ${ }^{2,4,7,19}$ Awareness of this disease entity and an understanding of the clinical presentation, proposed pathophysiologic mechanisms, and recommended treatments of djenkolism are important to guide practitioners in resource-poor areas in Southeast Asia.

\section{Disclosure}

The authors report no conflicts of interest in this work.

\section{References}

1. Adler SG, Weening JJ. A case of acute renal failure. Clin J Am Soc Nephrol. 2006;1(1):158-165.

2. Mathew AJ, George J. Acute kidney injury in the tropics. Ann Saudi Med. 2011;31(5):451-456.

3. Reimann HA, Sukaton RU. Djenkol bean poisoning (djenkolism); a cause of hematuria and anuria. Am J Med Sci. 1956;232(2):172-174.

4. Sakuja V, Sud K. Acute renal failure in the tropics. Saudi J Kidney Dis Transpl. 1998;9(3):247-260.
5. Suharjono A. Djenkol intoxication. Paediatr Indones. 1967;7(2):90-94.

6. Suharjono A, Sadatun OE. "Djenkol" intoxication in children. Paediatr Indones. 1968;8(1):20-29.

7. Eiam-Ong S, Sitprija V. Tropical plant-associated nephropathy. Nephrology. 1998;4(5-6):313-319.

8. Areekul S. Djenkol bean, djenkolic acid and djenkolism. J Med Assoc Thai. 1979;62(10):530-531.

9. Eiam-Ong S, Sitprija V, Saetang P, et al. Djenkol bean nephrotoxicity in Southern Thailand. Gopalakrishnakone P, Tan CK, editors. Progress in Venom and Toxin Research. Proceedings of the First Asia Pacific Congress on Animal, Plant and Microbial Toxins. Singapore: National University of Singapore Press; 1987;628:632.

10. H'ng PK, Nayar SK, Lau WM, Segasothy M. Acute renal failure following jering ingestion. Singapore Med J. 1991;32(2):148-149.

11. Segasothy M, Swaminathan M, Kong NC, Bennett WM. Djenkol bean poisoning (djenkolism): an unusual cause of acute renal failure. $\mathrm{Am} J$ Kidney Dis. 1995;25(1):63-66.

12. West CE, Perrin DD, Shaw DC, Heap GH, Soemanto. Djenkol bean poisoning (djenkolism): proposals for treatment and prevention. Southeast Asian J Trop Med Public Health. 1973;4(4):564-570.

13. Wong JS, Ong TA, Chua HH, Tan C. Acute anuric renal failure following jering bean ingestion. Asian J Surg. 2007;30(1):80-81.

14. Yong M, Cheong I. Jering-induced acute renal failure with blue urine. Trop Doct. 1995;25(1):31.

15. Barceloux DG. Djenkol bean [Archidendron jiringa (Jack) I. C. Nielsen]. Dis Mon. 2009;55(6):361-364.

16. Areekul S, Kirdudom P, Chaovanapricha K. Studies on djenkol bean poisoning (djenkolism) in experimental animals. Southeast Asian JTrop Med Public Health. 1976;7(4):551-558.

17. Areekul S, Muangman V, Bohkerd C, Saenghirun C. Djenkol bean as a cause of urolithiasis. Southeast Asian J Trop Med Public Health. 1978;9(3):427-432.

18. Vachvanichsanong P, Lebel L. Djenkol beans as a cause of hematuria in children. Nephron. 1997;76(1):39-42.

19. Jha V, Chugh KS. Nephropathy associated with animal, plant, and chemical toxins in the tropics. Semin Nephrol. 2003;23(1):49-65.
International Medical Case Reports Journal

\section{Publish your work in this journal}

The International Medical Case Reports Journal is an international, peer-reviewed open-access journal publishing original case reports from all medical specialties. Previously unpublished medical posters are also accepted relating to any area of clinical or preclinical science. Submissions should not normally exceed 2,000 words or

\section{Dovepress}

4 published pages including figures, diagrams and references. The manuscript management system is completely online and includes a very quick and fair peer-review system, which is all easy to use. Visit $\mathrm{http}: / /$ www.dovepress.com/testimonials.php to read real quotes from published authors. 